\title{
A compra de terras devolutas em Lages na segunda metade do Oitocentos ${ }^{1}$
}

\section{The purchase of vacant lands in Lages in the second half of the 19th century}

Flávia Paula Darossi ${ }^{2}$

Resumo: O artigo apresenta a
análise dos requerimentos de
compra de terras devolutas e de
posses referentes à região do
planalto catarinense,
especificamente do termo de
Lages e das freguesias de
Curitibanos e Campos Novos.
Os dados empíricos evidenciam
que, por tratar-se de uma
fronteira agrícola e de
povoamento em expansão no
século XIX, o planalto
catarinense foi ocupado a partir
de diferentes agenciamentos
políticos e sociais, o que
repercutiu em diferentes
estratégias de regulamentação
da propriedade.
Palavras-chave:
devolutas, Lei de Terras,
Planalto de SC.

Resumo: $O$ artigo apresenta a compra de terras devolutas e de posses referentes à região do planalto catarinense, especificamente do termo de Lages e das freguesias de Curitibanos e Campos Novos. Os dados empíricos evidenciam que, por tratar-se de uma povoamento em expansão no século XIX, o planalto catarinense foi ocupado a partir de diferentes agenciamentos políticos e sociais, o que repercutiu em diferentes estratégias de regulamentação da propriedade.

devolutas, Lei de Terras, Planalto de SC.

\begin{abstract}
The article presents the analysis of the requirements for the purchase of country's vacant lands and possessions related to the region of the Santa Catarina Plateau, specifically the Lages term and the Curitibanos and Campos Novos parishes. The empirical data show that, because it is an expanding agricultural and settlement frontier in the 19th century, the Santa Catarina plateau was occupied by different political and social assemblages, which had repercussions on different property regulation strategies.
\end{abstract}

Key-words: Vacant lands, Land Law, SC Plateau.

A dimensão histórica do conceito de propriedade possui caráter dinâmico e conjuntural, e seu estudo a partir do planalto catarinense é importante porque evidencia o processo de construção da estrutura agrária regional, mediado através dos complexos agenciamentos sociais e políticos que envolveram o uso e a posse da terra, seu domínio e regularização. Por isso, faz-se necessário desnaturalizar o binômio "pecuária-latifúndio" no sentido de repensar os padrões de ocupação da região, a multiplicidade de forças produtivas e de subsistência.

De natureza administrativa, os requerimentos de compra de terras devolutas são resultado da principal disposição da Lei de Terras de 1850: o acesso às terras devolutas por meio da compra ao Estado. Estes documentos apresentam as justificativas dos requerentes e as veredas dos processos pelos quais estes percorreram para a tentativa de validação de

\footnotetext{
${ }^{1}$ Trata-se de uma versão reduzida de um dos capítulos da Monografia da autora. DAROSSI, Flávia Paula. Regularização fundiária no Planalto Catarinense durante o período Monárquico (1850-1889). Monografia de Graduação. UFSC. Florianópolis, 2015.

${ }^{2}$ Discente de Mestrado do PPGH-UFSC, bolsista CNPq.

E-mail: flavia.darossi@gmail.com.
} 
direitos e concepções acerca da propriedade. A documentação evidencia também, a importância das relações sociais entre os diferentes sujeitos inseridos na hierarquia social do planalto para a construção da propriedade, desde pequenos agricultores até grandes criadores e fazendeiros, bem com os burocratas responsáveis pela administração e a execução da Lei de Terras na província e no município.

Existem 24 requerimentos de compra de terras devolutas no Arquivo Público do Estado de Santa Catarina (APESC) referentes à região do Planalto, especificamente do termo de Lages e das freguesias de Curitibanos e Campos Novos, selecionados a partir do recorte temporal de 1850-89.

\section{Origem da ocupação e estratégias de validação da propriedade}

A propriedade é uma ficção jurídica construída e reconhecida socialmente em um contexto histórico específico. As fontes empíricas evidenciam que o processo de regularização fundiária em Lages foi permeado pelas especificidades da região. Por se tratar de uma fronteira agrícola e de povoamento em expansão no século XIX, o planalto catarinense foi ocupado de diferentes maneiras, que repercutiram em diversos agenciamentos e estratégias de regularização da terra. Nesta perspectiva, cerca de $41,6 \%$ dos requerimentos analisados solicitaram a compra de parcelas de terras devolutas cuja posse foi afirmada em grande número por morada habitual e cultura efetiva. Ou seja, pelo recurso da compra, os requerentes buscaram a validação de extensões de terras já ocupadas. Por exemplo:

Diz Manoel José de Souza, morador no Termo da Vila de Curitibanos, criador e lavrador, que interessado em uma sorte de terrenos pertencentes ao Estado, constantes de matos, faxinais e catanduvas situados ao Norte da dita Vila no lugar denominado "Timbó", por quanto já ali tem casa e criação de gado vacum, vem por isso, [...] requerer a compra do aludido terreno na extensão de três mil braças_de frente com os fundos necessários. ${ }^{3}$

Diz Antonio França Soares morador do Distrito da freguesia dos Baguaes do município da Cidade de Lages desta mesma Província que o Suplicante há mais de vinte anos ocupa uma sorte de terras nacionais no mesmo distrito dos Baguaes, sendo tem o Suplicante cultura efetiva e casa de morada cita no lugar denominado _ Lajeado do Serro Negro_ nos matos do rio Caveiras [...] em cuja posse se tem conservado o Suplicante desde o começo dela em mansa e pacifica posse; e como nesse terreno ocupado pelo Suplicante não tem roças de outrem; quer o Suplicante comprar do Governo um lote de terras com a extensão de duzentas e cinquenta braças de frente e quatrocentos de fundos. ${ }^{4}$

\footnotetext{
${ }^{3}$ DE SOUZA, Manoel José. APESC. [Requerimentos: concessões de terras. 1880/85] 1884 jan., Curitibanos, vol. 13.

${ }^{4}$ SOARES, Antonio França. APESC. [Requerimentos: concessões de terras. T.C. 1867/76] 1874 out., Campos Novos, vol. 65.
} 
O posseiro e criador Manoel José de Souza requereu a extensão de terras concernente à aproximadamente uma légua de sesmaria para a criação de gado e, possivelmente, produção de lavoura, considerando que auto intitulou-se lavrador. Seu requerimento foi enviado ao presidente da província, Francisco Luiz da Gama Roza, que o encaminhou à câmara municipal e ao juiz comissário de Curitibanos. Este, Júlio Xavier Nunes, concedeu o seguinte parecer sobre a qualidade das terras requeridas: serviam "a criação de toda espécie de gados, porem depois de alguns anos, e continuas queimas de fogos, sendo que por enquanto nada cria"; contrariando a alegação de que o posseiro tinha criação de gado vacum nas terras requeridas. Já a câmara municipal de Curitibanos declarou apenas que as aludidas terras encontravam-se devolutas "e que, portanto, dúvida alguma há na pretensão do Suplicante". A solicitação foi deferida, e o preço das terras arbitrado em dois réis a braça quadrada. Já Antonio França Soares, posseiro há mais de duas décadas, requereu a extensão de 48,4 ha de terras, pequena área com prática de cultura efetiva e morada habitual declarada. Seu requerimento de compra de posse foi contestado por um dos confrontantes, o Major João Ignácio de Araújo, e indeferido pelo presidente provincial.

A Lei de Terras de 1850 proibiu a abertura de novas posses ao outorgar que as terras nacionais poderiam ser obtidas apenas pelo título de compra. Ambas as posses foram requeridas respectivamente em 1884 e 1874 e constituíam ocupações ilegais, visto que foram realizadas após 1850, logo, não passíveis de regularização pela via de legitimação.

Mas o estudo dos vinte e quatro requerimentos lavrados no termo de Lages durante o período imperial evidencia que grandes posseiros como Manoel, ou pequenos como Antônio, sabiam que a Lei de Terras outorgara a legitimação de terras devolutas ocupadas por posse até 1850, ao passo que, ao citar as condições necessárias para tal, como morada habitual e práticas agrícolas, os requerentes procuraram validá-las como argumento jurídico para o deferimento das solicitações de compra de posse. A título de exemplo deste revés legal entre compra e legitimação, um requerimento de Lages do ano de 1879 afirma que o posseiro,

[...] Possuindo um terreno Nacional onde já tem morada habitual, cultura, criações de gado vacum, cavalar, e suíno, e isto á mais de dois anos; cujo lugar é muito frequentado pelos gentios, [...] quer, portanto comprar ao Estado esta má posse que são três quartos de légua de frente com [?] légua de fundos, a fim de depois medida pelo respectivo juiz, fica o Suplicante legitimado desta má posse. ${ }^{5}$

\footnotetext{
${ }^{5}$ MELLO, Francisco Ferreira de Souza. APESC. [Requerimentos: concessões de terras. T.C. 1878/80] 1879 jun., Lages, vol. 67.
} 
Há de se considerar que as posses apresentadas nos requerimentos de compra do termo de Lages encontravam apoio jurídico na própria legislação das Sesmarias, que previa a legitimação de ocupações de terras devolutas caso existisse trabalho agrícola no lote. Atos possessórios como lavouras, casas de morada e benfeitorias, caso fossem de "de boa fé", desprovidos de querelas, justificavam a ocupação e garantiam-lhe legitimidade jurídica. De 1822, em decorrência da abolição do regime sesmarial, até 1850, com a promulgação da Lei de Terras, a posse foi o único meio de domínio sobre terras nacionais.

Segundo Márcia Motta, na história da ocupação do Brasil, a prática da posse transformou-se em costume "compartilhado por todos aqueles que ansiavam pelo acesso à uma parcela de terra ou que desejavam expandir a extensão de suas sesmarias para além dos limites originais" (MOTTA, 2008, p. 229).

\section{A presença de posseiros nacionais pobres}

No que se refere à questão social, 37,5\% dos vinte e quatro requerimentos analisados apresentam afirmações de condição de pobreza, alguns dos quais com atestados anexados pelo vigário de Lages e por camaristas municipais, a exemplo do que foi alegado pelo Pe. Antonio Luiz Esteves de Carvalho sobre o requerente de compra de um faxinal devoluto em Lages:

Atesto que Januário Antonio da Silva é morador do lugar denominado Corisco para onde veio em companhia de sua mãe e uma irmã, Maria Roza do Nascimento e Belisaria Maria do Nascimento, da cidade de Porto Alegre e entrou no sertão Nacional e ali escolheu um lugar de terras lavradas para com sua indústria tratar-se de sua miserável mãe e irmã para do contrário morrerão de fome pois que não tem outro modo de vida senão ser muito trabalhador, e para que não sofram miséria e sua família entrou no dito lugar ignorando as penas em que estava incurso na forma das Leis das Terras. É justo portanto que o Ex.mo Governo atenda as circunstancias do Peticionário, pois que sendo m.to laborioso é de supor-se que ganhe já sua indústria para pagar o lote que requer em vista de algum prazo. Cidade de Lages 6 de Agosto de 1863. Antonio Luiz Esteves de Carvalho. ${ }^{6}$

A migração interprovincial e a ocupação de terras devolutas nas florestas do interior do Brasil meridional constituiu uma das principais estratégias de sobrevivência e de busca por autonomia contra grandes senhores e possuidores de terras por parte de uma expressiva população nacional pobre.

\footnotetext{
${ }^{6}$ DA SILVA, Januario Antonio. APESC. [Requerimentos: concessões de terras T.C. $=1834-1840 / 41-1847-$ 1855/56 - 1859/64 - 1867] 1862 set., Lages, vol. 01.
} 
$\mathrm{Na}$ documentação analisada, foi possível observar que cerca de 45,8\% dos requerentes eram analfabetos, e dependiam do escrivão e dos vereadores das câmaras municipais de Lages e Curitibanos para a assinatura dos requerimentos que pretendiam remeter ao presidente provincial. Se considerarmos os demais correquerentes e pessoas envolvidas nos autos dos processos, a porcentagem de analfabetismo aumenta significativamente, a exemplo do posseiro Fabiano:

Diz Fabiano Rodrigues da Luz, morador no Passa Dois deste Termo, que sendo pobre e miserável reconhecido por todos, não tendo outro modo de vida senão de sua lavoura, vem perante $\mathrm{V}$. Exa ${ }^{\mathrm{a}}$. mui respeitosamente impetrar a graça de lhe conceder um pedaço de terras nacionais no lugar acima dito; lugar este onde já tem suas benfeitorias, e não incomoda o pessoal ali estabelecido por ter o suplicante ali trabalhado a vinte tantos anos e ter sempre sido aquelas terras d'onde o suplicante obtém o alimento para seu corpo, sendo pobre e miserável como mostra com os atestados juntos, pede a V. Ex.cia lhe ceder a quantia de terras que em sua alta consideração entender, e confiando no coração bondoso de V. Ex.cia fica esperando ato de justiça e caridade, o que espera receber mercê. Villa de Curitibanos 27 de Junho de 1883. Arrogo do Suplicante por não saber escrever, João Baptista Carvalho. ${ }^{7}$

Importante ressaltar que muitos fazendeiros eram também analfabetos, com a diferença de que estavam mais propensos a contar com redes de sociabilidade que lhes garantiam a manutenção de seus anseios no âmbito local, ao contrário dos lavradores pobres nacionais, livres ou libertos. Especificamente, as declarações de condição de pobreza ampliam a discussão sobre a possibilidade de equidade na aplicação do direito no século XIX, bem como a relação entre justiça e legalidade nos processos de regularização fundiária do planalto catarinense, considerando a existência de posses constituídas de primeiro ocupante, cujo trabalho resumia-se à pequena lavoura de subsistência e, por vezes, algumas poucas criações animais, em terras nas quais a origem dominial remetia para grandes concessões de sesmaria de abastados fazendeiros, muitos destes absenteístas e/ou com terrenos em comisso, interessados na manutenção e ampliação da extensão de suas terras.

\section{Possibilidades de peculato}

É importante que se problematize o discurso indireto do escrivão que solicitava o requerimento em nome do posseiro iletrado. A partir de procedimentos padronizados, que imprimiam a aparência de neutralidade e isonomia frente às leis e aos órgãos burocráticos do Estado, distintas relações político-sociais permeavam o ato de o funcionário lavrar o documento. Por exemplo, nove dos requerimentos analisados apresentam o mesmo modelo de 
texto para solicitações de compra de terras devolutas, no qual há a proposta do valor de um réis à braça quadrada e o prazo de dez anos para o pagamento e a demarcação dos lotes, sob a justificativa de que tais condições constavam em um aviso do Ministério da Agricultura de 05 de Janeiro de 1868.

Os pedidos foram lavrados entre os anos de 1873 e 1876, e referiam-se às terras devolutas situadas "no Rio do Peixe [...] na estrada que está se fazendo de Campos Novos para Palmas"; 8 no lugar denominado "Erval";; na "estrada do rio Marombas", ${ }^{10}$ e nas matas da vila de Curitibanos, etc. O presidente da província indeferiu todos os requerimentos sob a alegação de que não existia aviso algum do Ministério da Agricultura autorizando a venda de terras devolutas a partir do preço e prazo citados.

Grande parte da região era constituída de terras devolutas nas primeiras décadas do século XIX. Sabia-se que, com a expansão da fronteira ao interior e os incipientes projetos de colonização visionados para o interior da província, logo o território seria valorizado política e economicamente, inclusive sendo alvo de especuladores de terras de outras províncias do Império. Estava o escrivão indireta e intencionalmente dificultando o acesso dos requerentes à compra das terras na região, ao empregar um decreto inexistente e de condições exorbitantes, considerando o prazo de dez anos para a demarcação das terras?

Uma escritura de desistência de compra de terras devolutas de 1880 reflete, enquanto exemplo, as possibilidades de conduta de transgressão e peculato por parte do juizado municipal de Lages. Domingos Mendes Ouriques e Leopoldino Francisco da Silva Ortiz, em registro remetido ao presidente da província declararam que, tendo "em 1874 requerido a compra de umas terras devolutas, no quarteirão do Serrito, na costa do Rio Canoas d'este Município [de Lages] e reconhecendo-se hoje o direito de posse nas mesmas terras ao capitão Antonio Rickens de Amorim, veem por isso os Suplicantes desistirem da referida compra". ${ }^{11}$ Ambos os declarantes eram analfabetos e o documento foi assinado a rogo por Raymundo Antonio Paes de Farias. O beneficiado, Rickens de Amorim, era o promotor

\footnotetext{
7 DA LUZ, Fabiano Rodrigues. APESC. [Requerimentos: concessões de terras. T. 1876-87] 1883 jun., Curitibanos, vol. 11.

${ }^{8}$ TOURINHO, Antonio Jose Martins. APESC. [Requerimentos: concessões de terras. T.C. 1867/76] 1876 abr., Campos Novos, vol. 65; e BRANCO, Antonio Porfírio Moreira. APESC. [Requerimentos: concessões de terras. T.C. 1867/76] 1874 abr., Curitibanos, vol. 65.

${ }^{9}$ DE ALMEIDA, Antonio Rodrigues. APESC. [Requerimentos: concessões de terras. T.C. 1867/76] 1874 jun., Campos Novos, vol. 65; e DE ALMEIDA, Francisco Rodrigues. APESC. [Requerimentos: concessões de terras. T.C. 1867/76] 1874 out., Campos Novos, vol. 65.

${ }_{10}$ PALHANO, Americo Teixeira. APESC. [Requerimentos: concessões de terras. T.C. 1867/76] 1874 jul., Curitibanos, vol. 65; e DE MELLO, Armelinda Maria. APESC. [Requerimentos: concessões de terras. T.C. 1867/76] 1874 abr., Curitibanos, vol. 65.

11 OURIQUES, Domingos Mendes \& ORTIZ, Leopoldino Francisco da Silva. APESC. [Requerimento: concessão de terra] 1880, mai., Lages, vol. 03.
} 
público da comarca de Lages e Capitão da Guarda Nacional, e já havia exercido os cargos de escrivão, secretário interino da câmara etc..$^{12}$

\section{Outras estratégias de regularização da terra}

Em diferentes requerimentos foram observadas articulações de posseiros autointitulados pobres com vistas à resistência coletiva em situações de litígio relacionadas à extensão de pequenas posses e domínios de grandes posseiros. Existiu um número considerável de requerentes individuais que procurou utilizar o espaço para a denominação dos confrontantes nos requerimentos, como estratégia de afirmação ou negação dos direitos de propriedade destes, os reconhecendo ou omitindo na descrição dos extremantes de seus próprios terrenos.

Os requerimentos de compra de posses de Anna da Silva Ribeiro, Antonio França Soares e João Rodrigues Moreira, evidenciam tal agenciamento. Os três posseiros requereram separadamente a compra de suas posses - situadas em Serro Negro, "nas matas" do rio Caveiras, este apresentado no mapa a seguir, na freguesia dos Baguaes (atual Campo Belo) mas todos o fizeram em Outubro de 1874. Anna da Silva Ribeiro requereu a extensão de 96,8 ha de terras. ${ }^{13}$ Ela afirmou ocupar o referido "lote de terras nacionais" há mais de vinte anos com casa de morada e cultura efetiva, sendo que "[...] desde o começo dela em mansa e pacifica posse [...], nesse terreno ocupado pela Suplicante [diz ela que] não tem outro ocupante nem roças de outrem [...]", de modo que o terreno apossado, cuja requerente pretendia efetuar a compra, "só serve para plantar milho e feijão, e fumo, e é em parte estéril, e nem o Governo pode precisar dele para um fim particular"; indiretamente declarando ser posseira de boa-fé. Anna da Silva Ribeiro indicou como confrontantes Umbelina Maria da Trindade, João Ignácio de Araújo, José Manoel Correia, João Rodrigues Moreira e Ignácio Maria Leite.

O requerimento foi enviado ao presidente da província, João Capistrano Bandeira de Mello Filho, que o encaminhou à câmara municipal de Lages a fim de que averiguasse se a ocupação foi, de fato, realizada em terras devolutas. O edital da solicitação de compra foi lavrado e exposto por cerca de trinta dias, com o objetivo de convocar possíveis reclamantes. Em anexo, a requerente apresentou atestados de sua condição de pobreza assinados pelo

\footnotetext{
${ }^{12}$ Rickens de Amorim legitimou a referida posse em 1881. BRASIL, APESC. Título de legitimação de posse de ANTONIO RICKIN DE AMORIM. Índice de Coordenação de legitimação e Cadastramento de Terras Devolutas (COLECATE), Livro 60, fls. 117, gaveta 439, PCT 198.

${ }^{13}$ RIBEIRO, Anna da Silva. APESC. [Requerimentos: concessões de terras. T.C. 1867/76] 1874 out., Lages, vol. 65 .
} 
vigário de Lages, o Pe. Antonio Luiz Esteves de Carvalho, pelo delegado de polícia Gaspar José Godinho, pelo juiz de paz e outros camaristas cujos cargos não foram identificados, conforme abaixo:

Diz D. Anna da Silva Ribeiro viúva do finado Joaquim José Correa moradora do distrito da Freguesia dos Baguaes do município desta mesma Cidade, a bem de seu direito precisa que V. S ${ }^{a}$. ateste se a Suplicante é ou não viúva e com filhos, e se é ou não pobre e se vive do trabalho de lavoura. P. a V. S. se digne atestar lhe o requerido. Espera Receber Mercê. A rogo da Peticionária por não saber ler nem escrever [...]. ${ }^{14}$

O requerimento foi também enviado ao juiz comissário de Lages para a verificação da qualidade do terreno e se a ocupação consistia em posse de boa fé. Caso não existisse qualquer empecilho ou contestação, a Tesouraria Pública da Fazenda da Província seria consultada sobre a regularidade da quitação de impostos da requerente e seria determinado o preço da braça quadrada das aludidas terras. O presidente da província outorgaria o título provisório de propriedade, vigente até o pagamento da dívida, quando emitir-se-ia o título definitivo.

O processo de compra das terras de Anna foi interrompido por uma reclamação apresentada pelo confrontante João Ignácio de Araújo, que igualmente contestou o requerimento de compra de posse de Antonio França Soares. ${ }^{15}$ Este último requereu a extensão de 48,8 ha de terras, ${ }^{16}$ e também declarou ser posseiro há mais de vinte anos em terras devolutas situadas no lugar denominado Serro Negro, onde tinha cultura efetiva e morada habitual. Assim como no requerimento de Anna da Silva Ribeiro, Antonio afirmou habitar em mansa e pacífica posse, limítrofe ao terreno de seu pai João França, de Polidoro da Silva Ribeiro (parente de Anna da Silva Ribeiro), de Umbelina Maria da Trindade e de outros. Foram apresentados, em anexo, atestados da condição de pobreza do requerente, com o mesmo conteúdo lavrado sobre Anna da S. R., a saber, que "o Suplicante é pobre, casado e com filhos e vive de seu trabalho da lavoura".

Ambos os pedidos foram indeferidos pelo presidente da província, segundo a justificativa de que “[...] as terras, cuja compra requer o Suplicante estão compreendidas, segundo informa o Juiz Comissário, na medição da posse de João Ignácio de Araújo [...]”.

Já o requerente João Rodrigues Moreira, citado como confrontante por Anna da Silva Ribeiro, requereu a compra de uma posse de terras devolutas nas matas do mesmo rio

\footnotetext{
${ }^{14}$ Ibidem.

15 João Ignácio de Araújo também reclamou a posse do posseiro Felisberto José Corrêa. Autos incompletos, atestado de pobreza. Freguesia dos Baguaes-Lages.

${ }^{16}$ SOARES, Antonio França. APESC. [Requerimentos: concessões de terras. T.C. 1867/76] 1874 out., Campos Novos, vol. 65.
} 
Caveiras com a extensão de 242 ha de terras. ${ }^{17}$ Assim como os outros posseiros citados, João Rodrigues afirmou ocupar há anos o terreno que requeria à província, de forma mansa e pacífica, com morada habitual e cultura efetiva. Denominou como confrontantes os também “ocupantes nos mesmos matos”, Anna da Silva Ribeiro, José Manuel Correia, Rogério Vidal Silveira, e terras nacionais. Entretanto, João teve sua solicitação de compra de posse contestada pelo fazendeiro Jeronimo Rodrigues da Cunha, ${ }^{18}$ que citou como confrontante "Major Araújo", o reclamante dos requerimentos supracitados de Anna e Antonio. Segundo o fazendeiro, o Major "sempre funcionou, ora como perito, ora como testemunha, por ser verdadeiro confrontante".

O juiz comissário avaliou que as terras requeridas por João Rodrigues Moreira não eram devolutas como o mesmo afirmou, e esta foi a justificativa utilizada pelo presidente da província para o indeferimento do requerimento. Em declaração enviada ao presidente da província e aos membros da câmara municipal de Lages, Jeronimo Rodrigues da Cunha alegou que as terras requeridas pelos posseiros João e Ignácio estavam compreendidas na

Mansa e pacífica posse de propriedade do Suplicante: existente no distrito de Baguaes (no lugar denominado Lageadinho) cuja propriedade mencionada acha-se medida e demarcada, de conformidade com a Lei, e por este principio legitimada a posse do Suplicante e os seus antecessores, sem vir a poder ser perturbado em tempo algum, sem ofensa da Lei e do direito de propriedade. O Ill.mo Senhor Ignácio José de Almeida confinante do Suplicante e requereu ao Juiz Comissário a legitimação de sua posse por estar garantida na Lei; esta é por ser cultivada [?] de 20 anos; [?] é impossível querer comprar do Governo o que por Lei é do Suplicante [...]. João Rodrigues Moreira não tem direito a compra do terreno que se acha dentro da linha de medição do Suplicante e porque não tem posse alguma; outrossim umas pequenas capoeiras havidas criminosamente [...]. Vem o Suplicante perante V. S ${ }^{\mathrm{a}}$. [?] contra essas supostas compras por serem de má fé; só com o fim de perturbar a mansa e pacifica posse do suplicante que hoje se acha legitimada, de conformidade com a Lei $[\ldots]{ }^{19}$

O fazendeiro credenciava o ato de medir e demarcar sua posse como fosse título de legitimação, o que em sua concepção lhe facultava o direito de não "vir a poder ser perturbado em tempo algum”. Ao não citar a extensão correta nem a forma como ocupou a posse, o reclamante Jeronimo nos permite cogitar a possibilidade de ele legalmente não ser proprietário da posse, visto que apenas a mediu e demarcou, e não afirmou quando o fez, podendo a mesma estar caída em comisso em função da ausência de atos possessórios, do não

17 MOREIRA, João Rodrigues. APESC. [Requerimentos: concessões de terras. T.C. 1867/76] 1874 out., Campos Novos, vol. 65.

${ }^{18}$ Assim como outro posseiro autodeclarado pobre, chamado Ignácio José de Almeida.

${ }^{19}$ Ibidem. 
pagamento da dívida, da falta do título definitivo de propriedade, ou ainda da ausência de inscrição no Registro Paroquial de Terras.

O terreno reclamado pelo fazendeiro não se tratava de uma posse pacífica, como o mesmo afirmou. Existiram inúmeras declarações sobre a existência de pequenas parcelas de posses realizadas na mesma área há mais de duas décadas, por parte de uma população pobre que solicitou legalmente sua regularização pela via de compra, prevista em lei. Ao não reconhecer as casas e lavouras destes trabalhadores como atos possessórios válidos para a legitimação das posses, Jeronimo Rodrigues da Cunha contradizia em causa própria a legislação fundiária vigente, visto que afirmou ser impossível o fato de os lavradores efetuarem a compra de uma "propriedade" que já era sua "por direito".

Rodrigues da Cunha foi reconhecido pelo juiz comissário de Lages como senhor e possuidor das terras. Ao não afirmar a extensão das mesmas, ele ampliou as possibilidades de expansão para muito além dos domínios originais e impediu legalmente a regularização das posses de diversos lavradores já existentes na região. Ele procurou deslegitimar o direito de seus confrontantes alcunhando-os de posseiros criminosos e de má-fé. Estas denominações divergem dos atestados de pobreza dos camaristas de Lages e evidenciam a necessidade de assistência do Estado no que concerne ao reconhecimento ou distribuição de uma pequena parcela de terras para a subsistência destes que, de todo modo, contribuíam para a progressão da produção de gêneros alimentícios na região e forneciam mão-de-obra para a crescente demanda de trabalho livre na conjuntura da abolição da escravidão.

As deliberações do juiz comissário foram de imprescindível importância para o indeferimento dos requerimentos de compra das posses dos pequenos lavradores. Apesar destes se reconhecerem mutuamente como posseiros de boa-fé há décadas, inclusive com as declarações da câmara municipal acerca de suas condições de pobreza, tiveram seus direitos negados pelo presidente da província. A partir do parecer do juiz comissário em exercício, o presidente da província justificou que as terras requeridas não eram devolutas e que possuíam um legítimo proprietário. Todavia, é paradoxal o fato de que estes pequenos posseiros ocupavam há mais de vinte anos terras consideradas de domínio particular. Ou seja, como foram possíveis diferentes aberturas de posses em mata fechada (como os posseiros afirmaram, em terras sem evidências de qualquer ato possessório anterior) no terreno dito legitimado por Jeronimo? Há quanto tempo o fazendeiro ocupava a posse? E há quanto ela estava legitimada? Por que ele não reivindicou as parcelas de sua posse quando iniciaram tais ocupações "criminosas"? 
Os reclamantes João Ignácio de Araújo e Jeronimo Rodrigues da Cunha legitimaram as respectivas posses de 3.235,44 ha e 3.965,26 ha apenas no ano seguinte, em $1875 .^{20}$ Todavia, é importante ressaltar a maleabilidade da propriedade no século XIX, uma vez que o pequeno posseiro com requerimento indeferido geralmente não abandonava a posse que abriu. A negação do juiz comissário e a recusa do presidente de província no que concerne ao requerimento, apenas invalidava sua tentativa de titulação de posse, ao passo que ele tendia a permanecer com sua família e os atos possessórios onde havia se instalado, muitas vezes tornando-se agregado.

\section{Cultura efetiva e morada habitual}

Grande parte dos requerimentos analisados declarou a produção ou a intenção de prática de culturas agrícolas, criações e casas de morada (atos possessórios exigidos para legitimação de posses prevista na Lei de Terras), como estratégia para o deferimento de compra de apossamentos ou terras devolutas.

Cerca de $54 \%$ das solicitações afirmaram a produção de lavoura ou a tinham como finalidade, nas quais: nove requerentes declararam unicamente o cultivo de milho, feijão e fumo, em posses de terras devolutas que variaram entre 48,4 ha e 242 ha; e quatro afirmaram ter sistema de plantio integrado à criação animal, com as espécies suína e de gado vacum e cavalar, em extensões de terras indefinidas (pois requereram "quanto fosse necessário").

A criação de animais e a produção de alimentos para subsistência foram imprescindíveis para a viabilidade do processo de regularização fundiária, visto que garantiam as bases de sobrevivência desta população rural e oportunizavam a acumulação monetária para a compra de lotes de terra e o pagamento dos emolumentos do processo. Compreender estas questões no âmbito de uma sociedade coercitiva e escravocrata, cuja política, muitas vezes, resumia-se a práticas clientelísticas, reflete a importância de cada braça de terra para a população pobre da região.

\section{Litígios entre diferentes tipos de posseiros}

\footnotetext{
${ }^{20}$ Conforme consta no índice de títulos de posses legitimadas da COLECATE (Coordenação de Legitimação e Cadastramento de Terras Devolutas) da APESC. Títulos de legitimação de posse N $^{\circ}$ 518- JERONIMO RODRIGUES DA CUNHA - LAGEADINHO - 03/08/1875 - LIVRO 760 - FLS 50 - GAVETA 440 - PTC 19;
} 
Uma das estratégias utilizadas no planalto catarinense foi a de procurar resolver querelas de terra por meio de solicitações de compra de terras devolutas remetidas ao presidente provincial. Cerca de $25 \%$ dos requerimentos apresentaram reclamações de compra de posses que já constavam em domínio particular de terceiros, ou em posses já demarcadas e legitimadas, sob acusações de invasão de propriedade. Também existiram reclamações da "partilha-do-leão", isto é, divisões de posses em condomínio nas quais foram usurpadas benfeitorias como paiol e casa de moradia com cultura efetiva de posseiros condôminos.

É possível auferir que alguns dos requerimentos de compra de posse foram investidos como estratégia para o reconhecimento de direitos de propriedade de pequenos posseiros, a partir da concepção de que o trabalho em terras devolutas efetivava a posse e constituía a propriedade. A estrutura burocrática das municipalidades de Lages, e posteriormente de Curitibanos e Campos Novos, mesmo sendo demasiadamente classista, procurou ser questionada a partir do agenciamento de uma expressiva população pobre, que ambicionava o reconhecimento legal de seus direitos de acesso a terra contra os argumentos de grandes posseiros, fazendeiros e criadores instalados na região, e que contavam o suporte direto e/ou indireto do Estado, por frequentemente serem os homens indicados a cargos como o de subdelegado de polícia dos distritos ou então eleitos para o juizado de paz e a câmara de vereadores.

\section{A extensão e o preço das terras requeridas}

Todas estas solicitações de posses com lavouras e criações enredaram-se em querelas entre diferentes posseiros, o que nos permite considerar que se tratavam de requerimentos decorrentes de atos possessórios e direitos de acesso à propriedade em disputa, cuja legalidade estava em construção. Em função da maleabilidade da legislação fundiária, ou seja, da confusão legal criada entre os termos jurídicos posse e propriedade, compra e legitimação, distintos posseiros e proprietários reivindicavam o reconhecimento legal das dimensões de terra por eles afirmadas, muitas das quais sobrepostas quando verificadas a localização e delimitação das áreas.

A análise evidencia que as terras requeridas na região do atual município de Curitibanos equivaliam a grandes propriedades, reproduzindo o padrão latifundiário das primeiras concessões de sesmarias na região de Lages. As terras requeridas correspondentes à

e No 690 - JOÃO IGNACIO DE ARAUJO - CAMPESTRE - 1875 - LIVRO 760 - FLS 50V - GAVETA 440 PCT 19. 
Lages e Campos Novos variaram entre 30,25 ha e 4.356 ha e apresentaram extensões menores do que as observadas nos requerimentos de Curitibanos. Isto posto, é possível afirmar que a região do planalto não foi ocupada exclusivamente a partir de grandes concessões de terras realizadas pelo governo imperial para estancieiros.

A migração interprovincial catalisou ocupações de pequenos agricultores pobres, haja vista os requerimentos de compras de posses com atestados de condição de pobreza, ou seja, solicitações de pessoas com poucas ou quaisquer possibilidades de acesso à propriedade a não ser pela ocupação e trabalho em terras nacionais, como observado na documentação referente à Lages e Campos Novos. Entretanto, é importante distanciar a análise de perspectivas polarizadoras, entre ricos fazendeiros e sitiantes nacionais sem terra, e atinar para a existência de setores médios de lavradores e criadores.

Além disso, no que se refere ao termo de Lages, a indeterminação de algumas das extensões requeridas contribuiu para o domínio desordenado de terras devolutas e de outros posseiros, cujo exemplo evidencia-se nas requisições de "fundos necessários" ou de parcelas de terras "convenientes"; isto é, sem qualquer definição tanto da extensão quanto da exata localização das terras, na prática, açambarcadas à revelia. O termo "fundos necessários" geralmente era utilizado para indicar os limites de um terreno a partir de acidentes demográficos, como um rio, uma crista de morro íngreme, etc. De todo modo, para cada caso faz-se necessária uma investigação pormenorizada.

Outra questão relevante é o valor atribuído às terras. Quando declarado nos autos dos requerimentos deferidos, o preço da braça quadrada foi estipulado em dois reis, e os prazos concedidos para a medição e demarcação dos lotes variaram entre dois, três e quatro meses, segundo os pareceres dos presidentes da província. Dois réis à braça quadrada era um preço baixo e relativamente acessível ao pequeno lavrador nacional. Por exemplo, as terras requeridas em condomínio em Campos Novos com a extensão de 250 braças quadradas (ou 30,25 ha) foram vendidas pelo preço de 500 reis. Mas, em uma economia camponesa, pouco monetizada, este valor significava muito, se considerarmos como exemplo as declarações de condição de pobreza lavrados por pequenos posseiros, que afirmavam não poder arcar com as despesas de emolumentos e a dívida da compra, caso suas solicitações fossem deferidas pelo Governo.

No que se refere à população pobre do planalto e às possibilidades de pagamento da dívida decorrente da compra de um lote terras devolutas, assim como sobre a capacidade de geração de renda para tal, é possível atinar que, como não existia um mercado regular de trabalho em meados do Oitocentos, essa população tendia a servir de mão-de-obra em 
momentos de maior procura por serviços em fazendas da região. Grande parte em trabalhos por jornal, que incluíam afazeres como levantar moirões e cercas e até cultivar itens de lavoura como cereais para o abastecimento interno, juntamente com trabalhadores escravos das fazendas. A sazonalidade do trabalho agropastoril ampliava as possibilidades deles trabalharem em suas roças e também em jornadas como peões, tornando possível a ampliação da renda familiar e, consequentemente, da possibilidade de pagamento da regularização das terras em que viviam.

\section{REFERÊNCIAS BIBLIOGRÁFICAS}

BORGES, Nilsen Christiani Oliveira. Terra, gado e trabalho: sociedade e economia escravista em Lages, SC, 1840-1865. Dissertação de Mestrado em História, Universidade Federal de Santa Catarina, 2005.

CABRAL, Oswaldo R. História de Santa Catarina. $3^{\mathrm{a}}$ Edição. Florianópolis: Lunardelli, 1987.

CARVALHO, José Murilo de. A construção da ordem: a elite política imperial; Teatro de sombras: a política imperial. Rio de Janeiro: Ed. UFRJ/ Relume-Dumará, 1996.

COSTA, Licurgo. O continente das Lagens: sua história e influência no sertão da terra firme. Florianópolis: Fundação Catarinense de Cultura, 1982.

DAROSSI, Flávia Paula. Regularização fundiária no Planalto Catarinense durante o período Monárquico (1850-1889). Monografia de Graduação em História. UFSC. Florianópolis, 2015. EHLKE, Cyro. A conquista do Planalto Catarinense: bandeirantes e tropeiros do "Sertão de Curitiba". Rio de Janeiro: Laudes, 1973.

GRAHAM, Richard. Clientelismo e política no Brasil do século XIX. Rio de Janeiro: Ed. UFRJ, 1997.

HOLSTON, James. "Legalizando o ilegal: propriedade e usurpação no Brasil". In: Revista Brasileira de Ciências Sociais. № 21. São Paulo, 1993.

MOTTA, Márcia Maria Menendes. Nas fronteiras do poder: conflito e direito à terra no Brasil do século XIX. $2^{\text {a }}$ Edição. Niterói: Ed. UFF, 2008.

REVEL, Jacques. Jogos de escalas: a experiência da microanálise. Rio de Janeiro: FGV, 1998.

SILVA, Lígia Osório. Terras devolutas e Latifúndio: efeitos da Lei de Terras de 1850. Campinas: Ed. UNICAMP, 1996. 